\title{
Optimization of Oil Channel Structure of Monolithic Radiator
}

\author{
X.F. Cao, Y.A. Jin, Z.P. Jiang, Y. Liu \\ State Key Laboratory of Automotive Simu lation and Control \\ College of Automotive Eng ineering \\ Jilin University \\ Changchun, China
}

\begin{abstract}
In order to find the effect of radiator oil channel structure, size of the oil passage, oil passage arranged and singlechannel allocation small oil passages on the characteristics of radiator heat transfer. In the paper, Simulation for different oil passage of piece radiator, to determine the variation of the heat transfer characteristics and heat transfer efficiency. Studies have shown that small oil passages has a better thermal performance than large oil channel, with the increasing size of oil passage heat transfer efficiency of the radiator increase and decrease then.
\end{abstract}

Keywords-radiator; simulation; oil channel structure

\section{INTRODUCTION}

When the transformer is running, it becomes overheat and cause temperature rising in the transformer because of the presence of resistance and magneto resistance loss [1]. With the increased capacity of the transformer, the transformer overheating problem becomes increasingly prominent. Transformer temperature is too high not only resulting in transmission losses increase, but also transformer insulation materials resistance drops, accelerating aging of insulation materials, causing partial discharge, causing the output capacity more lower, reducing the transformer efficiency and shorten the life of the transformer[2]. It is important for transformer to radiate and the structure of piece-radiator oil channel has directly affected on the cooling capacity of the radiator. Therefore, in this article CFD software is used to simulate different radiator oil flow channel structure and heat transfer characteristics of thermal analysis studies.

\section{PIECE-RADIATOR COOLING OIL CHANNEL STRUCT URE AND PRINCIPLE}

In this paper, for transformer is sz11-240000/220KV supporting panel-type radiator PC2500-26/480(Using natural circulation cooling) to optimize the design. Piece-radiator oil channel structure as shown:

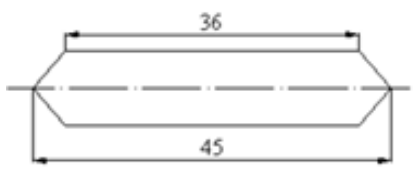

(a)Large oil channel

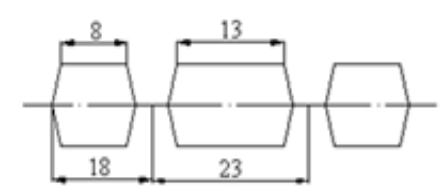

(b) Small oil channel
FIGURE I. HE SCHEMATIC DIAGRAM OFTHE DIFFERENT TYPES OF OIL CHANNEL.

In transformer, the temperature of transformer oil is high, often as high as $80{ }^{\circ} \mathrm{C}$. Liquid oil turn into oil steam, upward movement, introduced through the goose neck and radiator pipe into the plate radiator. And the plate radiator and the cold air outside are linked together. By convective heat and radiation heat transfer, oil stream turn into liquid oil, and liquid oil pass the return pipe into the transformer. Thus transformer oil between the transformer and the plate radiator will form the natural circulation flow the transformer. So the transformer will be cool [3].

\section{SIMULATION AND ANALYSIS}

Calculation parameters selection: (1)A ir side: inlet temperature is $30^{\circ} \mathrm{C}$, inlet velocity is $0.1 \mathrm{~m} / \mathrm{s}$; (2)Transformer cooling oil: inlet temperature is $80^{\circ} \mathrm{C}$, inlet velocity is $0.1 \mathrm{~m} / \mathrm{s}$, inlet density is $871 \mathrm{~kg} / \mathrm{m}^{3}$, kinematic $\mathrm{v}$ iscosity is $11 \times 10^{-6} \mathrm{~m}^{2} / \mathrm{s}$; (3)Wall boundary condition is the convection and radiation coupling boundary.

\section{A. The Structure of the Oil Passage Analysis}

In order to study the effects of different monolithic bulk oil passages within the structure of the transformer heat transfer, we choose two types of oil channel to analyze. In the simulation, it is assumed lard channel dimensions $45 \mathrm{~mm} \times$ $9 \mathrm{~mm}$, another small oil channels, each channel is divided into three small lard oil passages, three small oil passages wide in the middle, both sides of the two Road narrow little oil, the oil passage for middle path size $23 \mathrm{~mm} \times 9 \mathrm{~mm}$, both sides of the oil passages for $18 \mathrm{~mm} \times 9 \mathrm{~mm}$.

In order to characterize the effect of heat transfer, define heat exchange efficiency of heat transfer as follow:

Heat transfer efficiency $=\frac{\text { Monolithic bulk heat transfer }}{\text { Small oil channel monolithic structures scattered amount of heat }}$

The result of the different types of oil channel is shown in fig. 2.

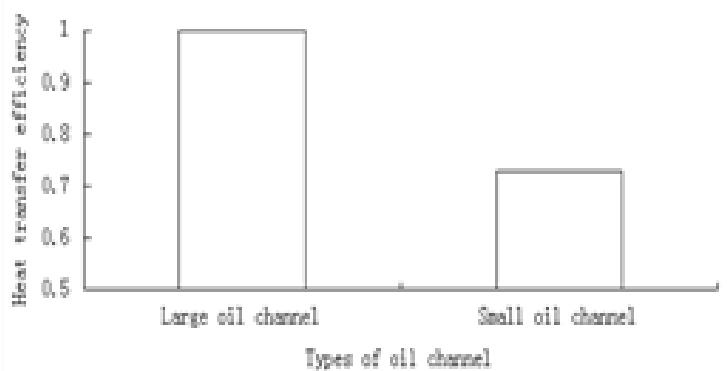

FIGURE II. CHANGES IN THE HEAT TRANSFER EFFICIENCY OF DIFFERENT TYPES OF OILPASSAGE. 
As the figure shows the small channel and the large channel heat transfer efficiency were 1.00 and 0.73 , so a s mall oil passages has higher heat transfer efficiency, this conclusion is also verified by the temperature contours. Low cloud seen by small internal oil passages, thus cooling the transformer oil cooling effect is good.
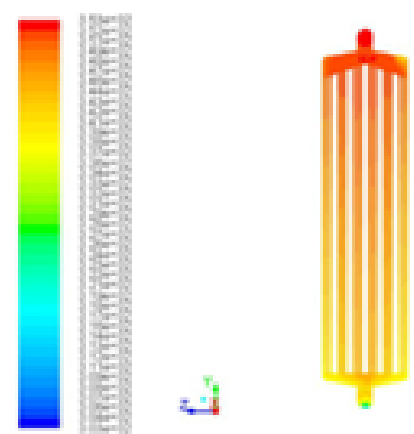

(a)Large oil passage

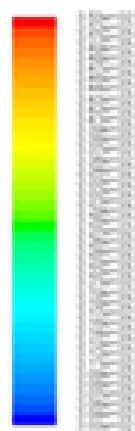

(b) Small oil passage

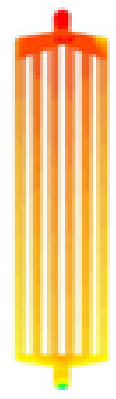

FIGURE III. ONOLITHIC BULK TEMPERAT URE CONT OURS.
The reason for this phenomenon is that when the same circulation area, when the channel is small, wet perimeter transformer cooling oil increases, increasing the contact area between the hot transformer oil and cryogenic cooling wall; at the same time, due to the large channel structure is composed of three small flow channels, transformer cooling oil in bulk oil agitating plate at the in let and outlet channels increases, the convective heat transfer coefficient increases which is beneficial to convection heat transfer, played the role of enhanced heat transfer.

\section{B. Analysis of the Oil Channel Dimensions}

To study the impact of heat dissipation with changing in the size of the monolithic bulk oil channel, channel dimensions $40 \mathrm{~mm} \times 9 \mathrm{~mm}, 45 \mathrm{~mm} \times 9 \mathrm{~mm}$ and $50 \mathrm{~mm} \times 9 \mathrm{~mm}$ were analy zed respectively.

In order to characterize the effect of different heat transfer oil duct size, the heat transfer efficiency is defined as follows:

Heat transfer efficiency $=\frac{\text { The quantity of heat transfer } \text { when the width of oil channel is } 45}{\text { The quantity of heat transfer } \text { when the width of oil channel is } 40,45,50}$

Analysis of the results of different oil radiator channel width is shown in fig. 4.

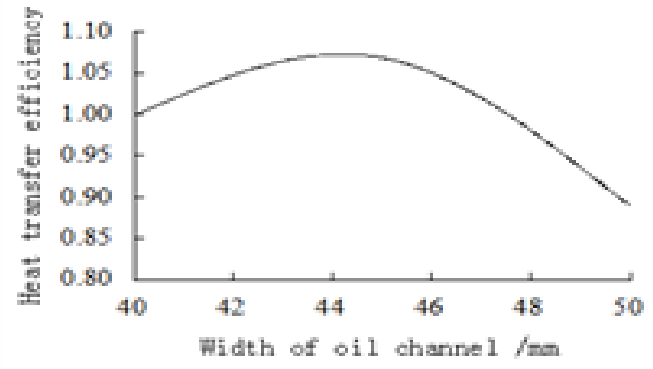

FIGURE IV.HANGES OF HEAT TRANSFER EFFICIENCY WITH DIFFERENT WIDTH OF OIL CHANNEL.

The figure shows with oil channel width increasing, heat transfer efficiency increased at first and then decreased. Oil channel width is $40 \mathrm{~mm}, 45 \mathrm{~mm}$ and when $50 \mathrm{~mm}$, heat transfer efficiency $1.00,1.07$ and 0.89 , respectively.

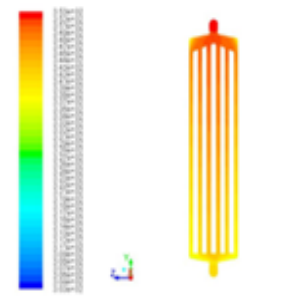

(a) $40 \mathrm{~mm}$

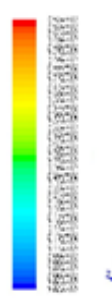

4

(b) $45 \mathrm{~mm}$

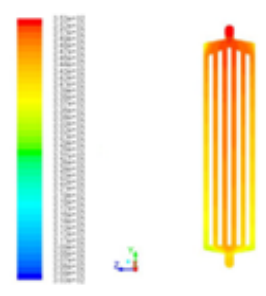

(c) $50 \mathrm{~mm}$
FIGURE V. EMPERATURE CONT OURS OF DIFFERENT OIL CHANNEL WIDTH.

The figure shows with the width of oil channel increasing, heat transfer efficiency increased at first and then decreased. Oil channel width is $40 \mathrm{~mm}, 45 \mathrm{~mm}$ and when $50 \mathrm{~mm}$, heat transfer efficiency 1.00, 1.07 and 0.89 , respectively. Varied widths of oil channel will result in changing transformer cooling oil flow and area of heat transfer. When the width of oil channel increases, transformer cooling oil flow rate decreases, weakening the convective heat transformer cooling oil and pieces scattered between; however, while the singlechannel heat transfer area of the oil will be produced along with oil channel width increases, played heat transfer enhancement effect.

\section{Arrangement of the Oil Passage}

In order to study the effect of changing arrangement of oil channel inside of the monolithic bulk on heat transfer cooling effect, Oil channels inside of monolithic radiator are distributed differently, Abbreviated as the size (1)large, small, (2) uniform and (3)s mall, large respectively. (1)is the way of giant distribution channel from the middle to the sides - for oil channel width $50 \mathrm{~mm}, 45 \mathrm{~mm}, 40 \mathrm{~mm}$ (Abbreviated as large, small), (2) oil evenly distributed channel width of $45 \mathrm{~mm}$, (3) from the middle to the sides of the oil channel width $40 \mathrm{~mm}$, $45 \mathrm{~mm}, 50 \mathrm{~mm}$ (Abbreviated as small, large).

In order to characterize the effect of different heat transfer oil duct size, the heat transfer efficiency is defined as follow:

Heat transfer efficiency $=\frac{\text { Monolithic bulk heat transfer }}{\text { When the oil passages scattered evenly distributed heat exchange monolithic }}$

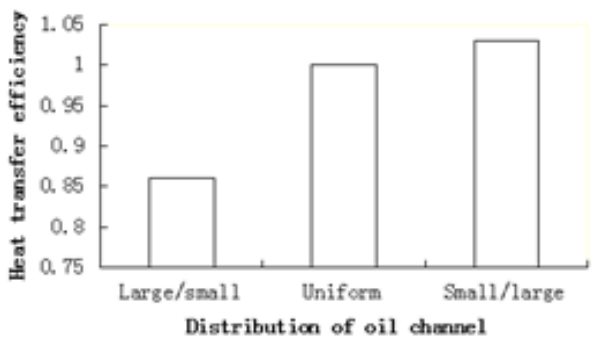

FIGURE VI.EAT TRANSFER EFFICIENCY OF DIST RIBUT ION OF THE DIFFERENT WAYS OF THE OIL CHANNEL.

As the figure shown the oil distribution channel (1) from the middle to the sides of the oil channel width of $50 \mathrm{~mm}$, $45 \mathrm{~mm}, 40 \mathrm{~mm}$ (Abbreviated as large, s mall), (2) oil uniform distribution channel width of $45 \mathrm{~mm}$, (3) from the middle to the sides of the oil channel width of $40 \mathrm{~mm}, 45 \mathrm{~mm}, 50 \mathrm{~mm}$ (Abbreviated as small, large), the heat transfer efficiency $0.97,1.00$ and 1.2, respectively. Thus, the oil channel 
distribution in the form of a narrow road in the middle of oil, both sides of the oil channels width as well.

Arrangement of the three cases, the first arrangement of three kinds (arranged as the way of large, small) 20\% higher than the uniform arrangement of the heat transfer efficiency, and heat transfer efficiency the first kind of arrangement of the first $3 \%$ lower than a uniform layout.
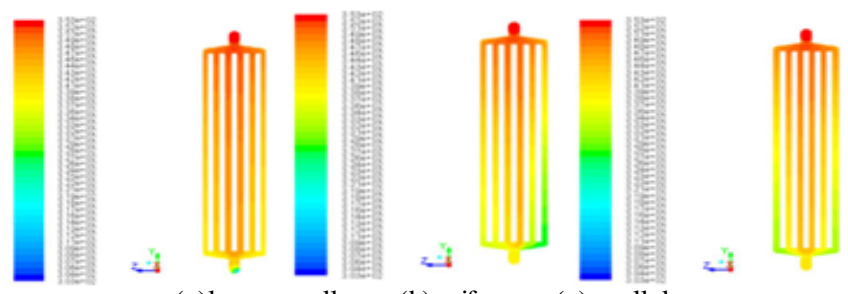

FIGURE VII.

(b)uniform (c)small, large

(a)large, small

TEMPERATURE CONTOURS OF DIFFERENT LAYOUT OF OIL CHANNEL.

From the above analysis, when the outside of the oil passages is designed large and middle of the oil passages is designed narrow, the effect of heat transfer is best.

\section{CONCLUSIONS}

In summary when radiator oil channel changes, the cooling oil inlet and outlet of the convection heat transfer coefficient and flow rate is also change, thereby changing the thermal performance of the radiator. The results show that: the small channel has higher heat transfer efficiency than large oil channel, with the increasing size of oil passage heat transfer efficiency of the radiator increase and decrease then.

\section{REFERENCES}

[1] Zhang ChangBin,Transformer,Research on new Cooler System for powertransformers, 42(8), pp.2, 2005.

[2] Zhang Xia, WangXiuChun, GuoXiaoXia, Flow distribution and cooling capacity for each channel of panel-type radiator CFD analysis,Transformers, 48 ( 3), pp.3,2011.

[3] Yang ShiMing.Heat Transfer. Higher Education Press. pp.1, 2006. 